\title{
Detecção de Brucella abortus em tecidos bovinos utilizando ensaios de PCR e qPCR ${ }^{1}$
}

\author{
Marrielen A.B. Caitano², Cleber O. Soares ${ }^{3}$, Carlos A.N. Ramos ${ }^{3}$, André L.J. Ferraz ${ }^{4}$, \\ Cristiane C. Sanches ${ }^{5}$ e Grácia M.S. Rosinha ${ }^{3 *}$
}

\begin{abstract}
Caitano M.A.B., Soares C.O., Ramos C.A.N., Ferraz A.L.J., Sanches C.C. \& Rosinha G.M.S. 2014. [Detection of Brucella abortus in bovine tissue using PCR and qPCR.] Detecção de Brucella abortus em tecidos bovinos utilizando ensaios de PCR e qPCR. Pesquisa Veterinária Brasileira 34(6):497-502. Faculdade de Medicina Veterinária e Zootecnia, Universidade Federal de Mato Grosso do Sul, Av. Felinto Müller 2443, Ipiranga, Campo Grande, MS 79070-900, Brazil. E-mail: gracia.rosinha@embrapa.br

The aim of the study was to evaluate the technical polymerase chain reaction (PCR) and Real-Time PCR (qPCR) to detect Brucella abortus from bovine tissues with suggestive lesions of brucellosis. For this, 21 fragments of bovine tissues collected at abattoirs of Mato Grosso do Sul were processed and subjected to microbiological culture and extraction of genomic DNA to perform the PCR reactions and qPCR. Eight samples of microbiological culture showed bacterial growth and five samples were confirmed as B. abortus by PCR. DNA of Brucella (IS711 primers) was detected in 13 (61.9\%) directly from tissue samples and $17(81 \%)$ from tissue homogenate samples. With the species-specific set of primers BruAb2_0168F and BruAb2_0168R, 14 (66\%) tissue samples and 18 (85.7\%) tissue homogenate samples were positive. Six positive samples in the species-specific PCR were sequenced and the best hit in the BLASTn analysis was B. abortus. By qPCR, $21(100 \%)$ tissue samples and 19 (90.5\%) tissue homogenate samples were positive for B. abortus. Ten samples of DNA from bovine blood from an accredited-free herd were used as negative control in PCR and qPCR analysis using the primers BruAb2_0168F and BruAb2_0168R, and no one amplified by PCR, whereas two samples were amplified by qPCR (20\%). In conclusion, both techniques detect the presence of $B$. abortus directly from tissues and homogenized, but the qPCR showed high sensitivity. The results indicate that qPCR can represent an alternative tool for faster and more accurate detection of $B$. abortus directly from tissues, and use in health surveillance programs by presenting satisfactory sensitivity and specificity.
\end{abstract}

INDEX TERMS: Brucellosis, Brucella abortus, isolation, sequencing, extraction, cattle.

RESUMO.- Objetivou-se no presente estudo avaliar as técnicas reação em cadeia da polimerase (PCR) e PCR em Tempo Real (qPCR) para detectar Brucella abortus, a par-

\footnotetext{
${ }^{1}$ Recebido em 9 de agosto de 2013.

Aceito para publicação em 1 de março de 2014.

${ }^{2}$ Programa de Pós-Graduação, Faculdade de Medicina Veterinária e Zootecnia (FMVZ), Universidade Federal de Mato Grosso do Sul (UFMS), Av. Felino Müller 2443, Ipiranga, Campo Grande, MS 79070-900, Brasil.

${ }^{3}$ Embrapa Gado de Corte, Av. Rádio Maia 830, Vila Popular, Campo Grande, MS 79106-550. *Autor para correspondência: gracia.rosinha@embrapa.br

${ }^{4}$ Universidade Estadual de Mato Grosso do Sul (UEMS), Rodovia Aquidauana Km 12, Aquidauana, MS 79200-000, Brasil.

${ }^{5}$ Doutoranda em Ciência Animal, Programa de Pós-Graduação, FMVZ-UFMS, Av. Felino Müller 2443, Ipiranga, Campo Grande, MS 79070-900.
}

tir de tecidos bovinos com lesões sugestivas de brucelose. Para isto, 21 fragmentos de tecidos bovinos coletados em abatedouros de Mato Grosso do Sul foram processados e submetidos ao cultivo microbiológico e extração do DNA genômico para realização das reações de PCR e qPCR. No cultivo microbiológico, oito amostras apresentaram crescimento bacteriano e cinco foram confirmadas como $B$. abortus por PCR. Diretamente das amostras de tecido, DNA do gênero Brucella (oligonucleotídeos IS711) foi detectado em $13(61,9 \%)$ amostras de tecido e $17(81 \%)$ amostras de homogeneizado. Já com os oligonucleotídeos espécie-específicos BruAb2_0168F e BruAb2_0168R, 14 (66\%) amostras de tecido e $18(85,7 \%)$ amostras de homogeneizado foram amplificadas. Seis amostras positivas na PCR espécie-espe- 
cífica foram sequenciadas e o best hit na análise BLASTn foi $B$. abortus. Na qPCR, 21 (100\%) amostras de tecidos e $19(90,5 \%)$ amostras de homogeneizado foram positivas para B. abortus. Dez amostras de DNA de sangue bovino de rebanho certificado livre foram utilizadas como controle negativo nas análises de PCR e qPCR utilizando-se os oligonucleotídeos BruAb2_0168F e BruAb2_0168R. Na PCR nenhuma amostra amplificou, enquanto que na qPCR 2 (20\%) amplificaram. Conclui-se que as duas técnicas detectam a presença de $B$. abortus diretamente de tecidos e homogeneizados, porém a qPCR apresentou maior sensibilidade. Os resultados obtidos indicam que a qPCR pode representar uma alternativa rápida e precisa para a detecção de $B$. abortus diretamente de tecidos, e ser utilizada em programas de vigilância sanitária, por apresentar sensibilidade e especificidade satisfatórias.

TERMOS DE INDEXAÇÃO: Brucelose, Brucella abortus, isolamento, sequenciamento, extração, bovinos.

\section{INTRODUÇÃO}

A brucelose é uma doença infecciosa causada por bactérias do gênero Brucella, que acometem seres humanos, animais domésticos e silvestres em todo o mundo. As espécies deste gênero apresentam geralmente um hospedeiro preferencial, o que confere à brucelose características próprias de disseminação, ou seja, possui potencial de existir em diferentes ambientes, podendo adaptar-se a diferentes hospedeiros. (Boschiroli et al. 2001, Walker 2003, Halling et al. 2005, Seleem et al. 2010). Brucella abortus é o principal agente da brucelose bovina (Poester et al. 2002, Acha \& Szyfres 2003). No entanto, outras espécies como Brucella suis e Brucella melitensis também podem infectar os bovinos quando estes estão em contato com suínos, caprinos e ovinos infectados (Acha \& Szyfres 2003). Vale ressaltar que B. melitensis ainda não foi isolada no Brasil (Poester et al. 2002, Brasil 2006,).

A brucelose bovina é uma doença infecciosa crônica responsável por importantes perdas econômicas à cadeia produtiva bovina, devido principalmente a abortos no terço final da gestação e nascimento de bezerros fracos (Acha \& Szyfres 2003, Soares Filho et al. 2012). Estima-se que a diminuição da produção de carne e leite por conta da enfermidade seja de $25 \%$, e o decréscimo na produção de bezerros seja da ordem de 15\% (Brasil 2006, Miranda et al. 2008). Outras perdas importantes, mas de difícil mensuração, estão relacionadas à depreciação do valor dos animais oriundos de propriedades com brucelose, e os gastos relativos ao tratamento e à redução da atividade produtiva de pessoas infectadas.

O governo brasileiro por meio do Ministério da Agricultura, Pecuária e Abastecimento (MAPA), criou em 2001 o Programa Nacional de Controle e Erradicação da Brucelose e Tuberculose (PNCEBT) com o objetivo de diminuir o impacto negativo dessas zoonoses na saúde humana e animal, além de promover a competitividade da pecuária nacional (Brasil 2006). 0 programa consiste basicamente na identificação e eliminação de animais infectados. Sendo assim, a correta identificação desses animais é uma das bases do programa de controle e erradicação de brucelose bovina (Lage et al. 2005, Poester et al. 2005).

O diagnóstico direto da brucelose pode ser feito por meio de imunohistoquímica, isolamento bacteriano e pela reação em cadeia da polimerase (PCR) (Alton et al. 1988). 0 padrão ouro para o diagnóstico da brucelose é o isolamento (Alton et al. 1988). No entanto, este método exige tempo e muitos recursos, como instalações laboratoriais com nível de biossegurança 3 (NB-3) e pessoal técnico altamente qualificado.

Mais recentemente a Norma Interna SDA no 2/2012 do MAPA (Brasil 2012) estabelece para fins de diagnóstico confirmatório, a coleta por meio dos Serviços de Inspeção Federal, e uso sistemático de amostras de carcaças de bovinos ou bubalinos com lesões sugestivas de brucelose. Em propriedades em que forem identificados focos ou suspeita de animais infectados, as carcaças serão retidas para exportação e os proprietários orientados ao saneamento do rebanho. Caso o resultado obtido seja negativo, os produtos retidos deverão ser liberados e a propriedade é novamente autorizada a enviar animais para abate com destino das carcaças aos mercados externos. Diante das exigências que surgem associadas aos problemas apresentados pelo isolamento microbiológico, novos testes de diagnóstico devem ser avaliados e implementados, a fim de obter resultados mais precisos e em curto espaço de tempo. A PCR é um método útil para o diagnóstico, pela rapidez, sensibilidade e especificidade. Além disso, possibilita a utilização de amostras em que os microrganismos foram inativados, tornando o diagnóstico mais seguro (Plikaytis et al. 1991, Ibrahim et al. 1992, Foster et al. 2008). Diversos métodos baseados na técnica da reação em cadeia da polimerase (PCR) como o AMOS-PCR, AMOS-ERY-PCR e PCR-Multiplex (Bricker \& Halling 1994), têm sido utilizados para identificação e classificação de espécies de Brucella, assim como diferenciação de biovares e cepas vacinais. Dentre as técnicas, a PCR em tempo real tem se destacado por apresentar altos níveis de sensibilidade e especificidade em relação a PCR convencional (Hinić et al. 2009).

No presente estudo, o objetivo foi avaliar as técnicas de PCR e qPCR para detecção de B. abortus diretamente em amostras de tecidos bovinos com lesões sugestivas. Espera-se com a presente avaliação, gerar subsídios para que o diagnóstico confirmatório de Brucella abortus em lesões sugestivas, possa ser realizado em menor tempo e com mais precisão do que o atualmente proposto pelo MAPA/ Brasil (isolamento microbiano).

\section{MATERIAL E MÉTODOS}

Amostras. Foram utilizadas amostras de tecidos de 21 bovinos, sorologicamente positivos para Brucella spp., provenientes de diversas propriedades do Estado de Mato Grosso do Sul - Brasil. Os animais foram abatidos em frigoríficos sob Inspeção Federal na cidade de Campo Grande, no período de agosto de 2008 a julho de 2012. Os tecidos coletados foram pulmão $(n=1)$, fígado $(n=4)$ e ligamento cervical $(n=16)$ que apresentavam lesões sugestivas de brucelose.

Processamento e cultivo microbiológico das amostras. A técnica utilizada para o cultivo microbiológico foi realizada de acordo com as metodologias empregadas para isolamento do 
patógeno (Alton et al. 1975, 0’Leary et al. 2006). As amostras de tecido foram identificadas e mantidas a $-80^{\circ} \mathrm{C}$ no Laboratório de Engenharia Genética Animal e processadas no Laboratório de Biossegurança, ambos da Embrapa Gado de Corte, Campo Grande, MS. Para processamento, as amostras foram retiradas do freezer 24 horas antes do procedimento para descongelamento lento. Os tecidos foram acondicionados em placas estéreis e dissecados com auxílio de tesouras e pinças esterilizadas. Fragmentos de tecidos com aproximadamente $25 \mathrm{mg}$ foram cortados sobre placas de petri descartáveis, e em seguida, foram transferidos para sacos de homogeneização e acrescidos de 200 mL de PBS pH 7,2 estéril. Foram homogeneizados usando o aparelho Stomacher (Modelo MC 1204, ITR, Brasil) por 5 minutos com 410 golpes/minuto. Após homogeneização $100 \mu \mathrm{L}$ foram semeados em placas contendo meio Trypticase Soy Agar (TSA), e tubos com Trypticase Soy Broth (TSB), acrescidos de Brucella Selective Supplement (HiMedia Laboratories FD 005) e 0,025 mg/mL de fungicida (anfotericina B).

Os cultivos foram incubados em estufa com $5 \%$ de $\mathrm{CO}_{2}$ a $37^{\circ} \mathrm{C}$, durante sete dias, e observados diariamente para constatar se houve crescimento bacteriano. Ao final desse período, nos casos em que não houve crescimento bacteriano, novas placas contendo meio TSA foram inoculadas com $200 \mu \mathrm{L}$ do caldo TSB mantido em crescimento por igual período. Após isso, as placas foram observadas por mais sete dias para a verificação de crescimento de colônias. Das colônias isoladas uma parte foi armazenada em meio de congelamento (meio BHI com adição de glicerol e água destilada) em criotubos e estocada a $-80^{\circ} \mathrm{C}$. A outra parte foi transferida para microtubos contendo $1 \mathrm{~mL}$ de PBS. Em seguida, as amostras foram centrifugadas a $16.100 x g$ por 5 minutos, o sobrenadante foi descartado, e o sedimento ressuspenso em $100 \mu \mathrm{L}$ de Tris EDTA (TE - 10 mM Tris $\mathrm{HCl} \mathrm{pH} \mathrm{7,4,1mM} \mathrm{EDTA} \mathrm{pH} \mathrm{8,0).} \mathrm{Posteriormente}$ as amostras foram inativadas a $100^{\circ} \mathrm{C}$ por 30 minutos e armazenadas a $-20^{\circ} \mathrm{C}$ para posterior extração de DNA.

Paralelamente, amostras do homogeneizado (1 $\mathrm{mL})$ obtidas no stomacher foram estocadas em criotubos e armazenadas a $-80^{\circ} \mathrm{C}$. Em seguida, $1 \mathrm{~mL}$ do homogeneizado foi centrifugado a $16.100 \mathrm{xg}$ por 5 minutos, o sedimento foi ressuspenso e inativado conforme descrito anteriormente. Após a inativação o material foi armazenado a $-20^{\circ} \mathrm{C}$ para posterior extração de DNA genômico.

Obtenção das amostras de tecido para extração de DNA. Fragmentos com aproximadamente $25 \mathrm{mg}$ dos órgãos com lesão foram acondicionados em placas de petri, e acrescidas de $800 \mu \mathrm{L}$ de PBS pH 7,2. Com o auxílio de uma pinça e bisturi os fragmentos de tecido foram totalmente cortados em fragmentos menores,
Extração de DNA. As amostras de tecido e homogeneizados foram previamente descongeladas e depois submetidas à extração de DNA genômico utilizando o kit Qiagen DNeasy Blood \& Tissue ${ }^{\circledR}$, conforme o protocolo descrito pelo fabricante. E para as amostras provenientes de isolamento bacteriano, foi utilizado o método de extração por guanidina, descrito por Pitcher et al. (1989).

Quantificação das amostras de DNA. As amostras foram quantificadas em aparelho espectrofotômetro (Nanodrop ${ }^{\circledR}$ ND1000), e em seguida as concentrações foram ajustadas para $100 \eta \mathrm{g} / \mu \mathrm{L}$.

PCR convencional. As amostras de DNA de tecido, homogeneizado e DNA bacteriano foram submetidas à técnica de PCR convencional, utilizando-se como alvo dois genes, sendo eles: IS711 e BruAb2_0168 (Hinić et al. 2008), que identificam o gênero e a espécie $B$. abortus, respectivamente. As sequências dos oligonucleotídeos denominados IS711 e BruAb2_0168 e, o tamanho aproximado dos fragmentos que estes amplificam, encontram-se descritos no Quadro 1. As reações de PCR foram realizadas em um volume total de $20 \mu \mathrm{L}$. Cada reação contendo $100 \eta$ g de DNA, 0,3 $\mathrm{mM} \mathrm{MgCl}_{2}$, 5pMol de cada oligonucleotídeos, 0,3 mM dNTP's e 1,5 U de Taq DNA polimerase.

Para os dois pares dos oligonucleotídeos IS711 e BruAb2_0168 as condições de termociclagem foram: $95^{\circ} \mathrm{C}$ por três minutos, seguindo de mais 35 ciclos compostos por desnaturação a $95^{\circ} \mathrm{C}$ por 30 segundos, anelamento a $60^{\circ} \mathrm{C}$ por 30 segundos e extensão a $72^{\circ} \mathrm{C}$ por 20 segundos. Ao final, uma etapa de extensão a $72^{\circ} \mathrm{C}$ por 10 minutos foi realizada. A análise do produto amplificado foi realizada por eletroforese em gel de agarose 3\% corado com Sybr Gold (Invitrogen) e visualizado em transluminador ultravioleta.

Como controle positivo das reações, utilizou-se o DNA extraído da cepa B. abortus S2308, adquirida de coleção biológica certificada e a amostra de referência USDA B19 (Departamento de Agricultura dos Estados Unidos - USDA), gentilmente cedidas pelo LANAGRO-MG (MAPA/Brasil). Como controles negativos, utilizou-se água DNAse free estéril e DNA de sangue de animais negativos em testes sorológicos para brucelose.

Clonagem e sequenciamento. Para a confirmação da especificidade da PCR convencional foram sequenciadas amostras positivas para os oligonucleotídeos BruAB2_0168, sendo estas 3 amostras de DNA de tecido e 3 amostras de DNA de diferentes isolados bacterianos. Os fragmentos amplificados foram inseridos no vetor $p G E M-T$ (Promega) e o plasmídeo recombinante foi sequenciado em ambas as direções pelo método de Sanger (Sanger et al. 1977) em sequenciador automático ABI3130 (Applied

Quadro 1. Oligonucleotídeos utilizados para amplificar amostras de Brucella spp. e Brucella abortus

\begin{tabular}{lcccc}
\hline Oligonucleotídeos & \multicolumn{1}{c}{ Sequência } & $\begin{array}{c}\text { Pares de } \\
\text { base }\end{array}$ & Gene & Referência \\
\hline $\begin{array}{l}\text { BruAb2_0168F } \\
\text { BruAb2_0168R }\end{array}$ & 5'GCACACTCACCTTCCACAACAA3' & 81 & BruAb2_0168 Hinić et al. 2008 \\
Hinić IS711 F & 5'CCCCGTTCTGCACCAGACT3' & & & \\
5'GCTTGAAGCTTGCGGACAGT3' & 63 & IS711 & Hinić et al. 2008
\end{tabular}

Hinić IS711 R

Sonda

FAM-TGGAACGACCTTTGCAGGCGAGATC- BHQ-1

deixando o material completamente macerado. Completou-se o volume para $1 \mathrm{~mL}$ com PBS e todo material foi transferido para um tubo tipo Eppendorf. Foram retirados $200 \mu \mathrm{L}$ do material e armazenado a $-20^{\circ} \mathrm{C}$ para a realização da extração do DNA.

Para a obtenção das amostras descritas como homogeneizado e tecido, o procedimento se deu no momento do cultivo, onde homogeneizado é uma alíquota de PBS+tecido (mistura em stomacker), e tecido é um fragmento de órgão lesionado que foi separado em tubo eppendorff e processado posteriormente.
Quadro 2. Detecção de Brucella spp. em amostras de tecidos com lesões. Cultivo microbiológico e ensaios de PCR com DNA dos isolados

\begin{tabular}{lccc}
\hline \multicolumn{1}{c}{ Método } & № de animais & \multicolumn{2}{c}{ Amostras positivas } \\
\cline { 3 - 4 } & & $\mathrm{N}$ & $\%$ \\
\hline Cultivo microbiológico & 21 & 8 & 38 \\
PCR IS711 & 8 & 5 & 62,5 \\
PCR BruAb2_0168 & 8 & 5 & 62,5
\end{tabular}




\begin{tabular}{|c|c|c|c|c|c|c|c|c|c|}
\hline \multirow[t]{2}{*}{ Amostra } & \multirow[t]{2}{*}{$\frac{\text { Isolamento }}{\mathrm{TSA}^{\mathrm{a}}}$} & \multicolumn{3}{|c|}{$\begin{array}{c}\text { PCR Convencional } \\
\text { (IS711) }\end{array}$} & \multicolumn{3}{|c|}{$\begin{array}{c}\text { PCR Convencional } \\
\text { (BruAb2_0168) }\end{array}$} & \multicolumn{2}{|c|}{$\begin{array}{l}\text { PCR em Tempo Real } \\
\text { (BruAb2_0168) }\end{array}$} \\
\hline & & $\mathrm{TSA}^{\mathrm{a}}$ & Tecido $^{b}$ & Homo $^{c}$ & $\mathrm{TSA}^{\mathrm{a}}$ & Tecido $^{b}$ & Homo $^{c}$ & Tecido $^{\mathrm{b}}$ & $\mathrm{Homo}^{c}$ \\
\hline 5 & - & - & + & + & - & - & + & + & + \\
\hline 6 & + & + & + & + & + & + & + & + & + \\
\hline 7 & + & + & + & + & + & + & + & + & + \\
\hline 8 & - & - & - & + & - & - & + & + & + \\
\hline 9 & - & - & - & + & - & + & - & + & + \\
\hline 13 & + & + & - & + & + & - & + & + & - \\
\hline 15 & + & - & + & + & + & + & + & + & + \\
\hline 30 & + & + & - & + & - & - & + & + & + \\
\hline SI & + & + & + & + & + & + & + & + & + \\
\hline 33 & - & - & + & + & - & + & + & + & + \\
\hline 34 & - & - & + & + & - & - & + & + & + \\
\hline 35 & - & - & + & + & - & + & + & + & + \\
\hline 36 & - & - & - & + & - & + & - & + & + \\
\hline 37 & - & - & - & + & - & + & + & + & + \\
\hline 38 & - & - & + & + & - & + & - & + & + \\
\hline 39 & - & - & + & + & - & + & + & + & + \\
\hline 40 & - & - & + & + & - & + & + & + & + \\
\hline 41 & + & - & - & - & - & - & + & + & + \\
\hline 42 & - & - & + & - & - & + & + & + & + \\
\hline 44 & - & - & - & - & - & - & + & + & - \\
\hline 45 & + & - & + & - & - & + & + & + & + \\
\hline
\end{tabular}

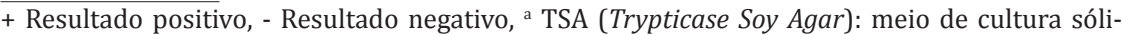
do utilizado no cultivo microbiológico, ${ }^{\mathrm{b}}$ Tecido: fragmento do órgão com lesão processado manualmente (Bisturi e pinça), ${ }^{\mathrm{c}}$ Homo: homogeneizado do fragmento do órgão com lesão processado por aparelho (Stomacher).

Biosystems, EUA). As reações de sequenciamento foram realizadas utilizando-se o kit Big Dye Terminator v3.1 (Applied Biosystems ${ }^{\circledR}$ ).

Os eletroferogramas obtidos foram analisados por meio do software BioEdit Sequence Alignment Editor e posteriormente as sequências de nucleotídeos foram analisadas por meio da ferramenta online BLASTn: Basic Local Alignment Search Tool, para busca de homologias.

PCR em Tempo Real (qPCR). 0 ensaio realizado com os oligonucleotídeos BruAb2_0168 para amplificações espécie-específicas foi descrito por Hinić et al. (2008) e adaptado para este estudo. A reações foram preparadas em volume final de $12,5 \mu \mathrm{L}$

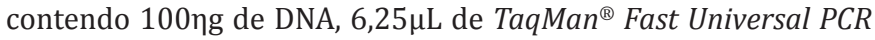
Master Mix (2x), 300nM de cada oligonucleotídeos, $200 \mathrm{nM}$ de sonda. As condições de termociclagem foram as seguintes: $50^{\circ} \mathrm{C}$ por 2 minutos, desnaturação a $95^{\circ} \mathrm{C}$ por 10 minutos, seguidos de 40 ciclos a $95^{\circ} \mathrm{C}$ por 15 segundos e $60^{\circ} \mathrm{C}$ por 1 minuto. Todas as amostras foram avaliadas em duplicata, em termociclador StepOne Plus (Applied Biosystems, EUA). Como controles positivos e negativos foram utilizadas as mesmas amostras controles da PCR convencional. Com o intuito de eliminar possíveis erros da técnica e evitar resultados falsos positivos, para interpretação dos resultados foram calculadas a média e desvio padrão do Ciclo de quantificação (Cq) das amostras provenientes de animais sorologicamente negativos, sendo consideradas positivas as amostras que apresentaram Cq 1,5 desvios padrão menor do que a média dos Cqs dos negativos.

Para avaliar a sensibilidade e especificidade da técnica de PCR em tempo real, adicionalmente foram analisadas 10 amostras de DNA de sangue bovino proveniente da Embrapa Gado de Leite (Certificada livre de Brucelose e Tuberculose bovina), e 2 amostras referência S2308 e USDA B19.

Análise estatística. Os resultados das reações de PCR e qPCR realizadas com os oligonucleotídeos BruAb2_0168, utilizando os DNAs de tecido, homogeneizado e sangue bovino negativo, foram comparados pelo teste Exato de Fisher. Um intervalo de confiança de $95 \%$ foi estabelecido.

\section{RESULTADOS}

\section{Isolamento bacteriológico}

Das 21 amostras de tecidos processadas, oito (38\%) apresentaram crescimento de colônias com características de Brucella spp. como: coloração translúcida, bordas regulares, colônias com tamanho pequeno e crescimento entre quatro a sete dias em estufa de $\mathrm{CO}_{2}$. As colônias isoladas foram provenientes das amostras de fígado (3 amostras) e ligamento cervical (5 amostras).

\section{PCR convencional}

Das oito amostras isoladas de crescimento bacteriano, cinco foram positivas para gênero Brucella spp. e para espécie $B$. abortus por PCR. As três amostras onde ocorreu o isolamento bacteriano e que não apresentaram positividade na PCR para gênero e espécie também apresentaram características morfológicas semelhantes à Brucella spp.

Das 21 amostras analisadas, 13 (61,9\%) amostras de DNA de tecido e 17 (81\%) amostras de DNA de homogeneizado foram positivas para o gênero Brucella. Para a espécie $B$. abortus, 14 (66\%) amostras de DNA de tecido e 18 (85,7\%) de DNA de homogeneizado foram positivas. Nenhum dos controles negativos apresentou amplificação, enquanto que os controles positivos foram confirmados por esta técnica.

\section{Sequenciamento}

As amostras de DNA de tecido e DNA dos isolados bacterianos sequenciadas apresentaram identidade de $99 \%$ com o acesso Genbank AE017224.1 de B. abortus. 


\section{PCR em tempo real}

Nos testes das amostras de DNA de tecido, as amostras negativas, bem como o controle negativo (água) apresentaram sinal de fluorescência nos ciclos finais da PCR, sendo que a média e desvio padrão de Cq destas foram de 34,7 e 0,95 , respectivamente. Com o intuito de reduzir as chances de resultados falsos positivos (amostras negativas que apresentaram fluorescência) a linha de corte foi considerada 1,5 desvios padrão menor do que a média do Cq dos negativos $(\mathrm{Cq}=33,3)$. Todas as amostras de DNA de tecido testadas foram positivas neste teste.

Por outro lado, nos testes com amostras de DNA de homogeneizado não houve sinal de fluorescência nas amostras negativas e controle negativo. Para este teste 19 amostras (90\%) foram positivas apresentando Cq entre 13,7 e 40 .

Nos testes de sensibilidade e especificidade 8 das 10 (80\%) amostras de DNA de sangue de bovinos provenientes de propriedade certificada livre para brucelose bovina, apresentaram sinal de fluorescência menor do que a linha de corte sendo consideradas realmente negativas. Por outro lado todos os controles positivos foram confirmados como tais.

\section{Análise estatística}

Ao teste Exato de Fisher não foi observada diferença significativa entre as duas técnicas (PCR e qPCR) para a detecção de B. abortus em amostras de DNA de homogeneizado. Em relação às amostras de tecido, a qPCR apresentou maior frequência de amostras positivas $(p=0,0086)$ em relação a PCR convencional. Não foram observadas diferenças significativas entre os tipos de amostra em cada técnica (PCR ou qPCR) $\mathrm{p}>0,05$.

\section{DISCUSSÃO}

Neste estudo foram avaliados ensaios de PCR e qPCR para detecção de $B$. abortus em amostras de tecidos com lesões sugestivas de brucelose, com o intuito de propor um diagnóstico post mortem rápido e preciso para a doença. Os resultados obtidos nos ensaios de PCR e qPCR foram comparados para avaliar a sensibilidade e especificidade das técnicas quanto à detecção de amostras positivas e negativas respectivamente. A utilização da técnica de qPCR com amostras de DNA de tecido, tendo como alvo o gene BruAb2_0168, mostra-se promissora para auxiliar no diagnóstico da brucelose, pois o gene citado é baseado em um único loci genético de B. abortus, mostrando ser espécie-específico.

Os ensaios de PCR e qPCR foram capazes de detectar um número maior de amostras positivas do que o cultivo microbiológico, que detectou apenas oito isolamentos. Após PCR com DNA extraído dos isolados microbianos, apenas cinco foram identificados como Brucella spp. e B. abortus (Quadros 2 e 3). A baixa sensibilidade do isolamento microbiológico tem sido relatada por outros autores (Bricker 2002, Navarro et al. 2002), e geralmente é atribuída a diferentes técnicas de isolamento (meios de cultivos diferentes), tipos de amostras e viabilidade do organismo na amostra (Ilhan et al. 2008, Hinić et al. 2009).
Os 3 resultados positivos no isolamento e negativos na PCR convencional podem ter ocorrido devido a falhas no processo de amplificação do DNA por PCR. Pois, o meio utilizado para o isolamento é específico e seletivo para Brucella, descartando-se a possibilidade de que possa ter havido confusão na identificação do microrganismo. A identificação microbiológica de isolados de Brucella pode ser feita por características morfológicas, PCR e testes bioquimicos (Lucero et al. 2008) no entanto, este último não foi realizado no presente estudo.

Com relação aos tecidos para isolamento, Paulin \& Ferreira Neto (2003) descrevem que os linfonodos retrofaríngeos, mandibulares, parotídeos, pré-escapulares e ilíacos, e principalmente os supramamários, são os tecidos em que $B$. abortus é mais frequentemente isolada. No presente estudo, o cultivo microbiológico foi realizado a partir de amostras de fígado e ligamento cervical e evidenciaram que outras amostras também podem ser fonte de estudo para detecção de B. abortus, principalmente quando apresentam lesão sugestiva.

Não foi observada diferença significativa entre os tipos de amostras (tecido ou homogeneizado) utilizadas $(p>0,05)$ na PCR convencional e qPCR. No entanto, na PCR convencional, tanto com os oligonucleotídeos genéricos IS711, como específicos BruAb2_0168, foi possível detectar maior número de amplificações nas amostras de DNA extraídas de homogeneizado, em relação as amostras de DNA de tecido. Isso pode ter acontecido devido à melhor homogeneização da amostra, que por sua vez resultou em um processo de lise mais eficiente durante a extração de DNA. Dessa forma, todas as unidades bacterianas presentes naquele fragmento de tecido, foram expostas e lisadas adequadamente. No tecido, por outro lado, a maceração ocorreu com o auxílio de pinça e bisturi. Esse processo resulta em fragmentos de tecidos maiores, e que por sua vez, limitam a eficiência da lise celular por não expor todas as células aos agentes lisantes. Na qPCR, uma maior frequência de resultados positivos foi observada com as amostras de DNA extraídas de tecido (21/21), em relação ao homogeneizado (19/21). Embora a qPCR possa ser influenciada pela qualidade das amostras de DNA, tanto quanto a PCR convencional, é possível que a alta sensibilidade intrinsecamente associada a técnica, possa ter resultado em uma diferença casual (Melendez et al. 2010).

Ao comparar as técnicas de PCR e qPCR com os oligonucleotídeos espécie-específicos, foi observado que a qPCR detectou de $90,5 \%(19 / 21)$ a $100 \%(21 / 21)$ das amostras de DNA positivas, apresentando maior sensibilidade em relação a PCR convencional que detectou de $66 \%$ $(14 / 21)$ a $85 \%(18 / 21)$. Por outro lado, dentre as amostras provenientes de bovinos de propriedade certificada como livre da brucelose, a qPCR detectou $20 \%$ de resultados falso-positivos $(2 / 10)$, enquanto a PCR convencional não detectou qualquer resultado falso-positivo. No entanto, as duas amostras com resultado falso-positivo na qPCR apresentaram Cq de 31,6 e 32,5, muito próximo ao Cq limite estabelecido como negativo $(33,3)$. Erros mínimos de pipetagem, até mesmo falhas no algoritmo de análise dos softwares, são apontados como possíveis causas 
de resultados falso-positivos em reações de qPCR (Dorak 2006).

Apesar de a qPCR ter apresentado uma especificidade inferior a PCR convencional quando amostras de sangue de bovinos "sadios" foram utilizadas, em se tratando de amostras provenientes de animais sorologicamente positivos e com lesão sugestiva (foco do programa de monitoramento), essa diferença na especificidade deve ser desprezível.

Portanto, além de uma maior sensibilidade, a qPCR possibilita a obtenção de resultados mais rápidos (1 dia), em relação ao teste padrão ouro atualmente preconizado (isolamento microbiano) que necessita de ao menos 4 a 7 dias. Já com relação a PCR convencional, a qPCR tem como principal vantagem a maior sensibilidade, apesar de apresentar um custo superior, o que com o benefício alcançado torna a técnica acessível para a utilização em grandes escalas.

\section{CONCLUSÃO}

Os resultados do presente estudo indicam que a qPCR espécie-específica baseada nos oligonucleotídeos BruAb2_0168, pode ser implementada como um teste rápido para o diagnóstico de Brucella abortus em amostras de tecidos, contribuindo para a diminuição da exposição do laboratorista ao risco que o patógeno confere, e possibilitando a obtenção de resultados mais rápidos. No entanto, recomenda-se que avaliações com maior número de amostras sejam realizadas para a validação definitiva da técnica.

Agradecimentos.- Ao Conselho Nacional de Desenvolvimento Científico e Tecnológico (CNPq) pelo apoio financeiro, por meio do Edital CNPq/ MAPA/SDA №64/2008, e à Empresa Brasileira de Pesquisa Agropecuária (Embrapa), por meio do Macroprograma 3 (Proc.03.08.01.004.00.00). À Renata Cunha Madureira, Méd. Veterinária, Fiscal Federal Agropecuário, pelo fornecimento das amostras utilizadas neste estudo.

\section{REFERÊNCIAS}

Acha P.N. \& Szyfres B. 2003. Zoonoses and communicable diseases common to man and animals. $3^{\text {rd }}$ ed. Pan American Health Organization, Washington, DC. 40p.

Alton G.G., Jones L.M., Angus R.D. \& Verger J.M. 1988. Techniques for the Brucellosis Laboratory: bacteriological methods. Inram, Paris. 190p.

Alton G.G., Jones L.M. \& Pietz D.E. 1975. Laboratory Techniques in Brucellosis. $2^{\text {nd }}$ ed. World Health Organization, Geneva. 175p.

Boschiroli M.L., Foulongne V. \& O'callaghan D. 2001. Brucelosis: a worldwide zoonosis. Curr. Opin. Microbiol. 4:58-64.

Brasil 2006. Manual Técnico do Programa Nacional de Controle e Erradicação da Brucelose e Tuberculose (PNCEBT): legislação. Departamento de Defesa Animal, Secretaria de Defesa Agropecuária, Ministério da Agricultura, Pecuária e Abastecimento, Brasília, p.36-42.

Brasil 2012. Secretaria de Defesa Agropecuária, Ministério da Agricultura, Pecuária e Abastecimento, Brasília: MAPA/SDA/Norma Interna SDA $\mathrm{n}^{\circ} 2 / 2012$.

Bricker B.J. 2002. PCR as a diagnostic tool for brucellosis. Vet. Microbiol. 90:435-446.

Bricker B.J. \& Halling S.M. 1994. Differentiation of Brucella abortus bv. 1, 2 and 4, Brucella melitensis, Brucella ovis and Brucella suis bv. 1 by PCR. J. Clin. Microbiol. 32:2660-2666.

Dorak M.T. 2006. Real Time PCR. Taylor and Francis Group, Abingdon. $362 p$.

Foster J.T., Okinaka R.T., Svensson R., Shaw K., De K.B., Robison R.A., Probert W.S., Kenefic L.J., Brown W.D. \& Keim P. 2008. Real-Time PCR assays of single-nucleotide polymorphisms defining the major Brucella clades. J. Clin. Microbiol. 46:296-301.

Halling S.M., Peterson-Burch B.D., Bricker B.J., Zuerner R.L., Qing Z., Li L.L., Kapur V., Alt D.P. \& Olsen S.C. 2005. Completion of the genome sequence of Brucella abortus and comparison to the highly similar genomes of Brucella melitensis and Brucella suis. J. Bacteriol. 187:2715-2726.

Hinić V., Brodard I., Thomann A., Cvetnić Z., Makaya P.V., Frey J. \& Abril C. 2008. Novel identification and differentiation of Brucella melitensis, $B$. abortus, B. suis, B. ovis, B. canis, and B. neotomae suitable for both conventional and real-time PCR systems. J. Microbiol. Methods 75:375-378.

Hinić V., Brodard I., Thomann A., Holub M., Miserez R. \& Abri C. 2009. IS711-based real-time PCR assay as a tool for detection of Brucella spp. in wild boars and comparison with bacterial isolation and serology. $B M C$ Vet. Res. 5:1-8.

Ibrahim A., Liesack W. \& Stackebrandt E. 1992. Polymerase chain reactiongene probe detection system specific for pathogenic strains of Yersinia enterocolitica. J. Clin. Microbiol. 30:1942-1947.

Ilhan Z., Aksakal A., Ekin I.H., Gülhan T., Solmaz H. \& Erdenlig S. 2008. Comparison of culture and PCR for the detection of Brucella melitensis in blood and lymphoid tissues of serologically positive and negative slaughtered sheep. Letters Appl. Microbiol. 46:301-306.

Lage A.P., Poester F.P., Gonçalves V.S.P., Roxo E., Müller E.E., Cavalléro J.C.M., Ferreira-Neto J.S., Motta P.M.P.C., Figueiredo V.C.F. \& Lôbo J.R. 2005. Programa Nacional de Controle e Erradicação da Brucelose e Tuberculose. Cad. Tec. Vet. Zootec. 47:99-110.

Lucero N.E., Ayala S.M., Escobar G.I. \& Jacob N.R. 2008. Brucella isolated in humans and animals in Latin America from 1968 to 2006. Epidemiol. Infect. 136:496-503.

Melendez J.H., Frankel Y.M., An A.T., Williams L., Price L.B., Wang N.Y., Lazarus G.S. \& Zenilman J.M. 2010. Real-time PCR assays compared to culture-based approaches for identification of aerobic bacteria in chronic wounds. Clin. Microbiol. Infect. 16:1762-1769.

Miranda K.L., Alves C.M., Minharro S., Lobo J.R., Müller E.E., Gonçalves V.S.P. \& Lage A.P. 2008. Quem ganha com a certificação de propriedades livres ou monitoradas pelo PNCEBT? Leite Integral 3:44-55.

Navarro E., Escribano J., Fernandez J.Á. \& Solera J. 2002. Comparison of three diferent PCR methods for detection of Brucella spp. in human blood samples. Immun. Med. Microbiol. 34:147-151.

O'Leary S., Sheahan M. \& Sweeney T. 2006. Brucella abortus detection by PCR assay in blood, milk and lymph tissue of serologically positive cows. Res. Vet. Sci. 81:170-176.

Paulin L.M. \& Ferreira Neto J.S. 2003. 0 Combate à Brucelose Bovina: situação brasileira. Funep, Jaboticabal, p.54.

Pitcher D.G., Saunders N.A. \& Owen R.J. 1989. Rapid extraction of bacterial genomic DNA with guanidium thiocyanate. Letters Appl. Microbiol. 8:151-156.

Plikaytis B.B., Eisenach K.D., Crawford J.T. \& Shinnick T.M. 1991. Differentiation of Mycobacterium tuberculosis and Mycobacterium bovis BCG by a polymerase chain reaction assay. Mol. Cell Probes 5:215-219.

Poester F.P., Gonçalves V.S.P. \& Lage A.P. 2002. Brucellosis in Brazil. Vet. Microbiol. 90:55-62.

Poester F.P., Samartino L.E. \& Lage A.P. 2005. Diagnóstico da brucelose bovina. Cad. Téc. Vet. Zootec. 47:13-29.

Sanger F., Nicklen S. \& Coulson A.R. 1977. DNA sequencing with chainterminating inhibitors. Proc. Natl Acad. Sci. USA 74:5463-5467.

Seleem M.N., Boyle S.M. \& Sriranganathan N. 2010. Brucelosis: a re-emerging zoonosis. Vet. Microbiol. 140:392-398.

Soares Filho P.M., Wanderley R.P.B., Faria G.C., Penna A.G., Ribeiro D.B.C.L., Assis R.A., Leite R.C., Fonseca Junior A.A. \& Ribeiro A.C.C.L. 2012. Confirmação de infecção por Brucella abortus em um rebanho bovino certificado livre em Minas Gerais: relato de caso. Arq. Bras. Med. Vet. Zootec. 64:1133-1136.

Walker R.L. 2003. Brucella, p.185-191. In: Hiursh D.C. \& EE Y.C. (Eds), Microbiologia Veterinária. Guanabara Koogan, Rio de Janeiro. 